(2) Open Access Full Text Article

\title{
Assessment of ocular hypotensive effect and safety 12 months after changing from an unfixed combination to a latanoprost $0.005 \%$ + timolol maleate $0.5 \%$ fixed combination
}

This article was published in the following Dove Press journal:

Clinical Ophthalmology

17 April 2012

Number of times this article has been viewed

Kenji Inoue'

Ryoko Okayama'

Risako Higa'

Masato Wakakura'

Goji Tomita²

Inouye Eye Hospital, 4-3 KandaSurugadai, Chiyoda-ku, ${ }^{2}$ Second

Department of Ophthalmology,

Toho University School of Medicine,

Meguro-ku, Tokyo, Japan
Correspondence: Kenji Inoue Inouye Eye Hospital,

4-3 Kanda-Surugadai, Chiyoda-ku,

Tokyo I0I-0062, Japan

$\mathrm{Tel}+332950911$

$\mathrm{Fax}+332950917$

Email inoue-k@inouye-eye.or.jp
Background: Latanoprost $0.005 \%$ + timolol maleate $0.5 \%$ combined eyedrops were recently made available in Japan. We prospectively investigated the intraocular pressure (IOP)-lowering effect, visual preservation effect, and adverse reactions of a one-year administration of this fixed combination.

Methods: The subjects included 162 eyes from 162 patients diagnosed with either primary open-angle glaucoma or ocular hypertension and using an unfixed combination of latanoprost $0.005 \%$ and timolol maleate $0.5 \%$. The unfixed combination was discontinued and replaced with the latanoprost $0.005 \%$ + timolol maleate $0.5 \%$ fixed combination with no washout period. IOP was measured before (baseline) and 3, 6, 9, and 12 months after the change. The mean deviation value of Humphrey field analysis was compared. Adverse reactions were examined at every follow-up.

Results: No significant differences were found between mean IOP values obtained at baseline (mean \pm standard deviation, $15.2 \pm 3.3 \mathrm{mmHg}$ ) 3 months $(15.1 \pm 3.2 \mathrm{mmHg}), 6$ months $(15.3 \pm 3.1 \mathrm{mmHg}), 9$ months $(15.3 \pm 3.1 \mathrm{mmHg})$, and 12 months $(15.1 \pm 3.2 \mathrm{mmHg})$ after the change from the unfixed to the fixed combination of eyedrops $(P=0.212)$. In addition, no significant differences were observed between mean deviation values obtained at baseline $(-9.11 \pm 6.94 \mathrm{~dB})$ and 12 months $(-10.08 \pm 7.24 \mathrm{~dB})$ after the change $(P=0.114)$. Thirty-one patients discontinued the fixed combination within 12 months of replacement, due to an insufficient IOP decrease (20 patients, 12.3\%) and adverse reactions (11 patients, 6.8\%).

Conclusion: Following replacement of two eyedrop medications (latanoprost $0.005 \%$ and timolol maleate $0.5 \%$ ) by one fixed combination (latanoprost $0.005 \%+$ timolol maleate $0.5 \%$ ), IOP and visual field were preserved. However, $20 \%$ of the patients discontinued the new treatment because of an insufficient IOP decrease and complaints of adverse reactions.

Keywords: latanoprost $0.005 \%$, timolol maleate $0.5 \%$, fixed combination, intraocular pressure, safety, visual field

\section{Introduction}

In recent years, fixed combination eyedrops have been developed to improve adherence to glaucoma therapy. In Japan, a fixed combination of eyedrops containing latanoprost $0.005 \%$ + timolol maleate $0.5 \%$ (Xalacom ${ }^{\circledR}$ combination eyedrops; Pfizer Japan Inc, Japan, Tokyo) has been available on the market since April 2010. In patients who were previously receiving latanoprost $0.005 \%$ and timolol maleate $0.5 \%$ eyedrops concomitantly (unfixed combination), changing to the latanoprost $0.005 \%+$ timolol maleate $0.5 \%$ fixed combination resulted in decreased administration frequency and 
increased adherence. Moreover, this fixed combination is expected to decrease intraocular pressure (IOP). However, although latanoprost $0.005 \%$ + timolol maleate $0.5 \%$ fixed combination eyedrops are administered once a day, timolol maleate $0.5 \%$ eyedrops were previously administered twice a day, therefore raising concerns about the level of IOP decrease provided by the fixed combination. Several studies have previously reported shortterm effects on IOP following a change to the fixed combination. ${ }^{1-4}$ In addition, in patients with primary open-angle glaucoma and ocular hypertension, we described an IOP-lowering effect 3 months after switching from the unfixed combination to the latanoprost $0.005 \%+$ timolol maleate $0.5 \%$ fixed combination. ${ }^{5}$ However, in many cases, glaucoma medication is used continuously for long periods. Therefore, long-term evaluation of the IOPlowering efficacy and safety of latanoprost $0.005 \%+$ timolol maleate $0.5 \%$ fixed combination eyedrops is needed. Further, $\beta$-blockers are known to show decreased efficacy in reducing IOP following long-term administration. ${ }^{6}$ Nevertheless, the reports available concern mostly assessment of effects at 6 weeks, ${ }^{1}$ more than 2 months, ${ }^{2} 3$ months, ${ }^{3,5}$ and 6 months ${ }^{4}$ after changing from the unfixed combination, which are all short time periods. There are no reports of long-term administration. Few reports concern administration of latanoprost $0.005 \%$ + timolol maleate $0.5 \%$ fixed combination eyedrops as monotherapy for longer periods of over a year. ${ }^{7-9}$ Longterm follow-up of effects on the visual field are also required, because this is the final goal of glaucoma treatment. To date, only one study has evaluated the effects of the fixed combination eyedrops on the visual field. ${ }^{9}$

The present study assessed the long-term effects of latanoprost $0.005 \%$ + timolol maleate $0.5 \%$ fixed combination eyedrops in patients diagnosed with primary openangle glaucoma and ocular hypertension. We prospectively investigated the IOP-lowering efficacy and preservation of the visual field, as well as safety, after changing from the unfixed to the fixed combination for one year. This study further extends our previous assessment that had a 3-month administration period. ${ }^{5}$

\section{Materials and methods}

Participants were the same as those enrolled in our previous study. ${ }^{5}$ We prospectively investigated 162 eyes from 162 patients ( 88 men, 74 women) diagnosed at the Inouye Eye Hospital from April to October 2010. They were diagnosed with either primary open-angle glaucoma (normal tension glaucoma included) or ocular hypertension, and had been using latanoprost $0.005 \%$ eyedrops and timolol maleate
$0.5 \%$ eyedrops concomitantly for more than 3 months. Their mean age ( \pm standard deviation) was $64.3 \pm 11.4$ years, ranging from 32 to 87 years. The patient disease types included normal tension glaucoma $(n=65)$, primary openangle glaucoma $(n=93)$, and ocular hypertension $(n=4)$. The criterion for diagnosing normal tension glaucoma was IOP $\leq 21 \mathrm{mmHg}$ and for primary open-angle glaucoma was IOP $>21 \mathrm{mmHg}$ when measured several times to evaluate circadian variation and specific changes of glaucoma in the retina nerve fiber layer. The criterion for diagnosing ocular hypertension was IOP $>21 \mathrm{mmHg}$ when measured several times to evaluate circadian variation and no specific changes for glaucoma in the retina nerve fiber layer. Previous treatment with glaucoma eyedrops involved the use of two (91 cases), three (58 cases), and four (13 cases) different medications. Timolol maleate eyedrops were administered as aqueous timolol $0.5 \%$ (administered twice a day) in 38 patients, ion gel-forming timolol 0.5\% (administered once a day) in 105 patients, or thermogel-forming timolol $0.5 \%$ (administered once a day) in 19 patients. Patients who had undergone glaucoma surgery were excluded. Patients who had had cataract surgery within 3 months were also excluded. If both eyes met the inclusion criterion, the eye with the highest IOP was assessed. If both eyes had the same IOP, the right eye was analyzed. In monocular cases, the affected eye was subjected to analysis.

The individual latanoprost $0.005 \%$ and timolol maleate $0.5 \%$ eyedrops formerly used were discontinued and changed to the latanoprost $0.005 \%+$ timolol maleate $0.5 \%$ fixed combination (administered once a day at night) with no washout period. Other eyedrop medications were maintained as previously. IOP was examined using a Goldmann applanation tonometer. The same investigator performed the IOP evaluations before the change from the unfixed to the fixed combination and 3, 6, 9, and 12 months after the change, at approximately the same time of day. IOP evaluation was performed in the total number of cases $(n=162)$, latanoprost $0.005 \%$ and timolol maleate $0.5 \%$ concomitant use cases $(n=91)$, primary open-angle glaucoma cases $(n=93)$, normal tension glaucoma cases $(n=65)$, and cases in which cataract surgery was performed $(n=28)$ or not performed $(n=134)$. The patients were monitored for adverse reactions at every check-up. The Humphrey 30-2 Sita-Standard visual field test program was applied before the change and 12 months after the change. Patients in whom false-positive results, false-negative results, or poor fixation accounted for $20 \%$ or more of the assessments were excluded from evaluation of visual fields. Statistical comparisons of mean IOP 
values were performed using analysis of variance followed by Bonferroni/Dunnett's tests. Mean deviation values were compared using the paired $t$-test. The significance level was set at $P<0.05$ for all statistical tests performed. The study was reviewed and approved by the institutional review board of Inouye Eye Hospital. All participants provided written informed consent to participate in the study, and the study was conducted in full compliance with the tenets of the Declaration of Helsinki.

\section{Results}

The mean deviation value before the change (baseline), as measured by the Humphrey 30-2 Sita-Standard visual field test program, was $-9.11 \pm 6.94 \mathrm{~dB}($ mean $-32.47 \pm 1.03 \mathrm{~dB})$. The mean IOP at baseline was $15.2 \pm 3.3$ (8-32) $\mathrm{mmHg}$. In the total number of cases $(n=162)$, no significant differences were found between mean IOP values at baseline $(15.2 \pm 3.3 \mathrm{mmHg})$ and 3 months $(15.1 \pm 3.2 \mathrm{mmHg})$, 6 months $(15.3 \pm 3.1 \mathrm{mmHg}), 9$ months $(15.3 \pm 3.1 \mathrm{mmHg})$, and 12 months $(15.1 \pm 3.2 \mathrm{mmHg})$ after the change from the unfixed to the fixed combination of eyedrops $(P=0.218$, Table 1). Six months after the change, IOP decreased by more than $2 \mathrm{mmHg}$ in 15 patients $(10.6 \%)$, increased by more than $2 \mathrm{mmHg}$ in 27 patients $(19.0 \%)$, and varied within $\pm 1 \mathrm{mmHg}$ in 92 patients (64.8\%, Figure 1). Twelve months after the change, IOP decreased by more than $2 \mathrm{mmHg}$ in 29 patients (21.8\%), increased by more than $2 \mathrm{mmHg}$ in 31 patients (23.3\%), and varied within $\pm 1 \mathrm{mmHg}$ in 66 patients $(49.6 \%)$. No significant differences were found between the mean deviation values obtained before $(-9.11 \pm 6.94 \mathrm{~dB})$ and 12 months $(-10.08 \pm 7.24 \mathrm{~dB})$ after the change $(P=0.114$, Figure 2). On the other hand, in patients using concomitant timolol maleate $0.5 \%$ and latanoprost $0.005 \%(n=91)$, primary open-angle glaucoma cases $(n=93)$, normal tension glaucoma cases $(n=65)$, and cases in which cataract surgery was performed $(n=28)$ or not performed $(n=134)$, there was no disparity in IOP after the change (Table 2).

Thirty-one cases (19.1\%) discontinued the new treatment within 12 months of starting the fixed combination protocol.
Reasons for treatment discontinuation included insufficient IOP decrease (20 cases, 12.3\%) and complaints of adverse reactions (11 cases, 6.8\%). The following adverse reactions were reported by the patients: eye pain $(n=3)$, itchiness $(n=2)$, stimulation $(n=2)$, photophobia $(n=1)$, foreign body sensation $(n=1)$, headache and nausea $(n=1)$, and dissatisfaction $(n=1)$. All adverse reactions disappeared when the patients were again administered the individual latanoprost $0.005 \%$ and timolol maleate $0.5 \%$ eyedrops.

\section{Discussion}

Previous studies ${ }^{1-5}$ have assessed the short-term effects on IOP-lowering efficacy of changing from an unfixed combination (latanoprost $0.005 \%$ and timolol maleate $0.5 \%$ ) to the latanoprost $0.005 \%$ + timolol maleate $0.5 \%$ fixed combination eyedrops. Different results were found, ie, no significant differences in mean IOP values, ${ }^{3-5}$ significant decreases, ${ }^{2}$ and significant increases.

Few reports have assessed the IOP-lowering efficacy following long-term administration of the latanoprost $0.005 \%$ + timolol maleate $0.5 \%$ fixed combination. ${ }^{7-9}$ Rigollet et al randomized 128 patients diagnosed with either primary open-angle glaucoma or ocular hypertension into three groups. ${ }^{7}$ Each group received a different formulation of fixed combination eyedrops, ie, latanoprost $0.005 \%+$ timolol maleate $0.5 \%$ fixed combination (42 patients), travoprost $0.004 \%$ + timolol maleate $0.5 \%$ fixed combination (44 patients), and bimatoprost $0.03 \%+$ timolol maleate $0.5 \%$ fixed combination (42 patients). Mean IOP before administration of the latanoprost $0.005 \%+$ timolol maleate $0.5 \%$ fixed combination was $27.6 \mathrm{mmHg}$. However, after 6 and 12 months of administration of this fixed combination, mean IOP values significantly decreased and mean IOP-lowering values were $8.27 \pm 4.56 \mathrm{mmHg}$ and $9.02 \pm$ $3.63 \mathrm{mmHg}$, respectively. After 12 months of administration, the IOP-lowering rate was $32.25 \%$. Adverse reactions recorded during the 6-month administration period included red eye (23.8\%), itching (14.3\%), and dryness (14.1\%). Higginbotham et al also randomized 418 patients diagnosed

Table I Intraocular pressure (IOP) at baseline, 3, 6, 9, and I2 months after the change

\begin{tabular}{|c|c|c|c|c|}
\hline & $\begin{array}{l}\text { Mean IOP } \pm \text { standard } \\
\text { deviation }(\mathrm{mmHg})\end{array}$ & Minimum (mmHg) & Maximum (mmHg) & $\begin{array}{l}\text { P compared with } \\
\text { IOP at baseline }\end{array}$ \\
\hline Baseline & $15.2 \pm 3.3$ & 8 & 32 & - \\
\hline 3 months after the change & $15.0 \pm 3.2$ & 8 & 26 & 0.218 \\
\hline 6 months after the change & $15.3 \pm 3.1$ & 10 & 25 & 0.218 \\
\hline 9 months after the change & $15.3 \pm 3.1$ & 9 & 24 & 0.218 \\
\hline 12 months after the change & $15.1 \pm 3.2$ & 8 & 23 & 0.218 \\
\hline
\end{tabular}




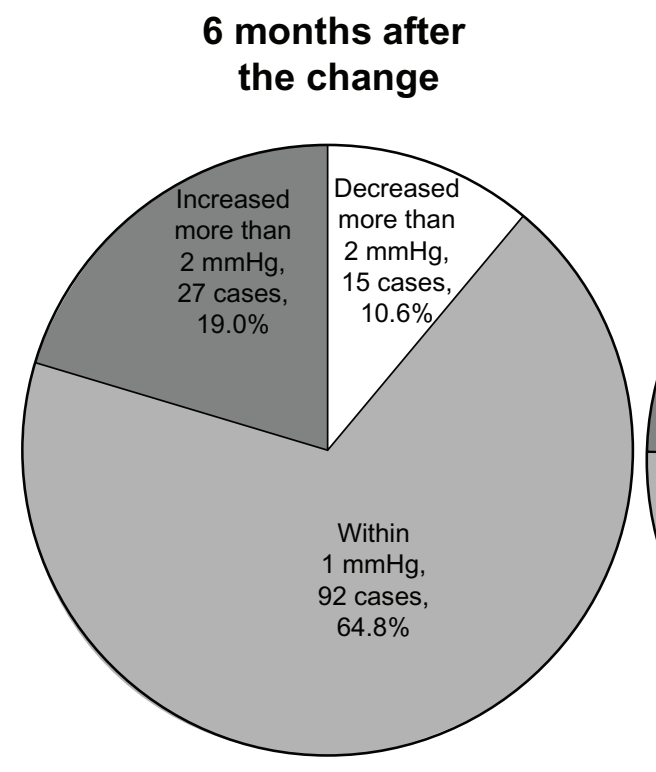

\section{2 months after the change}

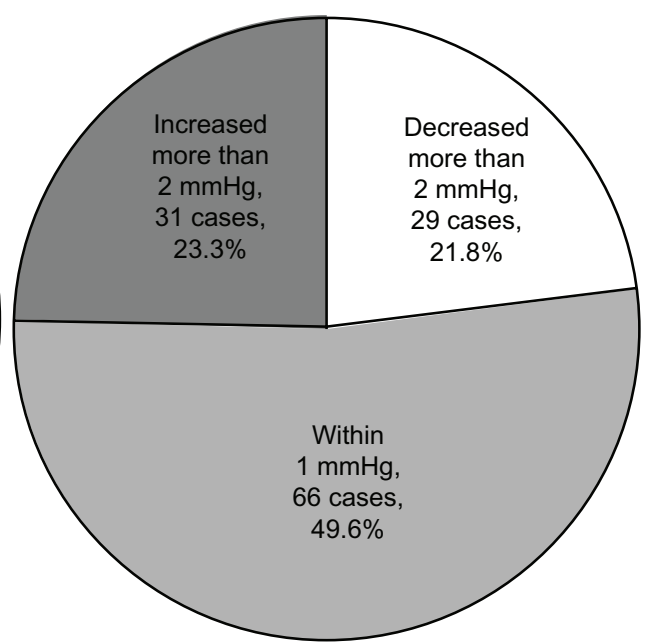

Figure I Frequency of intraocular pressure-lowering at 6 and 12 months after changing from the unfixed combination to the latanoprost $0.005 \%+$ timolol maleate $0.5 \%$ fixed combination eyedrops.

with primary open-angle glaucoma, pigmentary glaucoma, exfoliation glaucoma, or ocular hypertension into three groups, each receiving a different eyedrop formulation for 6 months, ie, timolol maleate $0.5 \%$ eyedrops (140 patients), latanoprost $0.005 \%$ eyedrops ( 140 patients), and latanoprost $0.005 \%+$ timolol maleate $0.5 \%$ fixed combination eyedrops (138 patients). ${ }^{8}$ At the end of this 6-month period, all patients were changed to the latanoprost $0.005 \%$ + timolol maleate $0.5 \%$ fixed combination, which was administered for another
6 months. In patients receiving the latanoprost $0.005 \%+$ timolol maleate $0.5 \%$ fixed combination since the beginning of the study, mean IOP values decreased significantly after $6(19.4 \pm 3.0 \mathrm{mmHg})$ and $12(18.9 \pm 3.2 \mathrm{mmHg})$ months of administration, compared with the IOP values before administration $(23.1 \pm 3.8 \mathrm{mmHg})$. Schwenn et al prospectively observed 2339 patients diagnosed with glaucoma or ocular hypertension who were previously treated with monotherapy, or unfixed or fixed combinations. ${ }^{9}$ All patients were

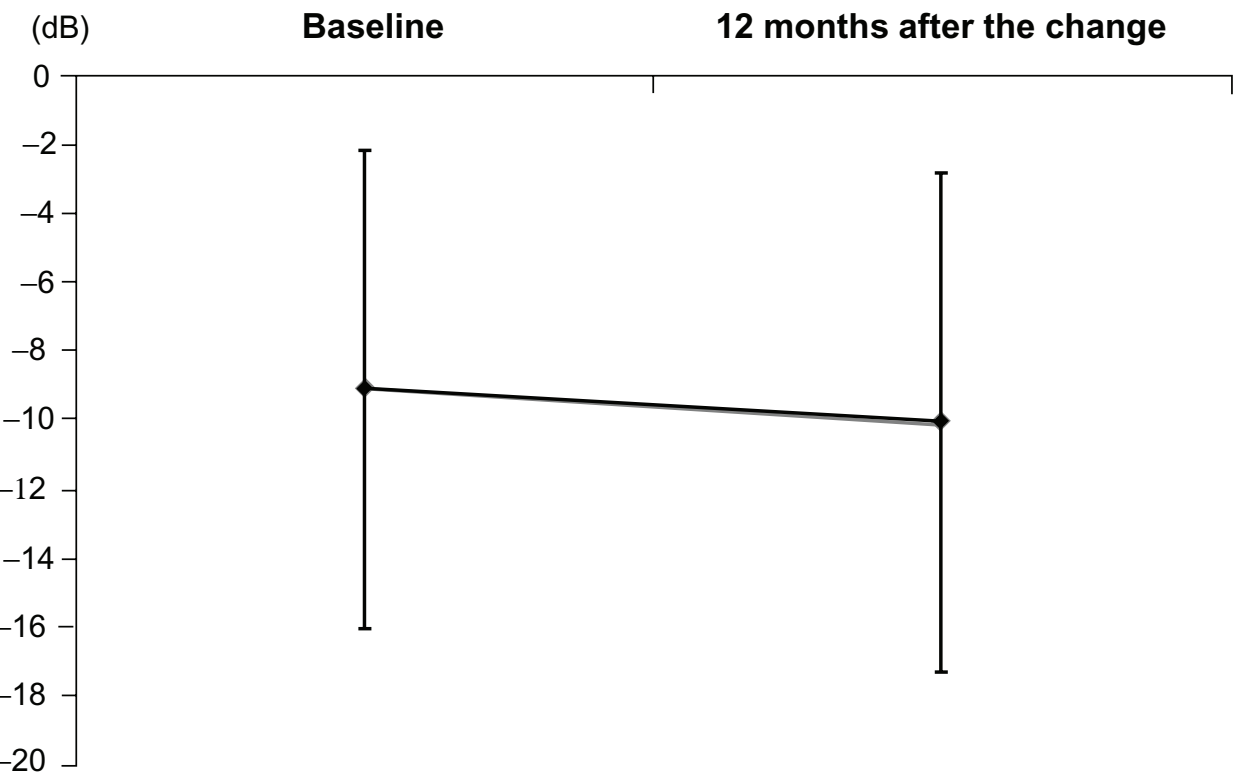

Figure 2 Mean deviation value obtained before and 12 months after changing from the unfixed combination to the latanoprost $0.005 \%+$ timolol maleate $0.5 \%$ fixed combination eyedrops. 
Table 2 Intraocular pressure (IOP) at baseline, 3, 6, 9, and 12 months after the change in timolol + latanoprost cases, POAG cases, normal tension glaucoma cases, performed cataract surgery cases, and not performed cataract surgery cases

\begin{tabular}{|c|c|c|c|c|c|c|}
\hline & Baseline & $\begin{array}{l}3 \text { months after } \\
\text { the change }\end{array}$ & $\begin{array}{l}6 \text { months after } \\
\text { the change }\end{array}$ & $\begin{array}{l}9 \text { months after } \\
\text { the change }\end{array}$ & $\begin{array}{l}12 \text { months after } \\
\text { the change }\end{array}$ & $\begin{array}{l}\text { P compared with } \\
\text { IOP at baseline }\end{array}$ \\
\hline $\begin{array}{l}\text { Timolol } \pm \text { latanoprost } \\
\text { (91 cases) }\end{array}$ & $\begin{array}{l}14.5 \pm 2.7 \\
\text { (9l cases) }\end{array}$ & $\begin{array}{l}14.5 \pm 3.0 \\
(79 \text { cases })\end{array}$ & $\begin{array}{l}14.5 \pm 2.7 \\
(76 \text { cases })\end{array}$ & $\begin{array}{l}14.6 \pm 2.7 \\
(73 \text { cases })\end{array}$ & $\begin{array}{l}14.5 \pm 2.9 \\
(7 \mid \text { cases })\end{array}$ & 0.1638 \\
\hline POAG (93 cases) & $\begin{array}{l}16.5 \pm 3.3 \\
(93 \text { cases })\end{array}$ & $\begin{array}{l}16.3 \pm 3.2 \\
(80 \text { cases })\end{array}$ & $\begin{array}{l}16.3 \pm 2.7 \\
(81 \text { cases })\end{array}$ & $\begin{array}{l}16.4 \pm 2.8 \\
(79 \text { cases })\end{array}$ & $\begin{array}{l}16.4 \pm 3.4 \\
(76 \text { cases })\end{array}$ & 0.0991 \\
\hline $\begin{array}{l}\text { Normal tension } \\
\text { glaucoma ( } 65 \text { cases) }\end{array}$ & $\begin{array}{l}13.1 \pm 1.9 \\
(65 \text { cases })\end{array}$ & $\begin{array}{l}13.2 \pm 2.2 \\
(56 \text { cases })\end{array}$ & $\begin{array}{l}13.5 \pm 2.7 \\
(57 \text { cases })\end{array}$ & $\begin{array}{l}13.5 \pm 2.3 \\
(53 \text { cases })\end{array}$ & $\begin{array}{l}|3 .| \pm 2.3 \\
(52 \text { cases })\end{array}$ & 0.1794 \\
\hline \multicolumn{7}{|l|}{ Cataract surgery } \\
\hline $\begin{array}{l}\text { Performed } \\
\text { (28 cases) }\end{array}$ & $\begin{array}{l}16.0 \pm 4.7 \\
(28 \text { cases })\end{array}$ & $\begin{array}{l}14.6 \pm 2.7 \\
\text { (26 cases) }\end{array}$ & $\begin{array}{l}15.4 \pm 3.6 \\
\text { ( } 26 \text { cases) }\end{array}$ & $\begin{array}{l}15.1 \pm 2.9 \\
(24 \text { cases })\end{array}$ & $\begin{array}{l}15.1 \pm 3.2 \\
(24 \text { cases })\end{array}$ & 0.1491 \\
\hline $\begin{array}{l}\text { Not performed } \\
\text { (134 cases) }\end{array}$ & $\begin{array}{l}15.0 \pm 2.9 \\
\text { (134 cases) }\end{array}$ & $\begin{array}{l}15.1 \pm 3.3 \\
(119 \text { cases })\end{array}$ & $\begin{array}{l}15.2 \pm 2.9 \\
(110 \text { cases })\end{array}$ & $\begin{array}{l}15.3 \pm 3.1 \\
(103 \text { cases })\end{array}$ & $\begin{array}{l}15.1 \pm 3.2 \\
(99 \text { cases })\end{array}$ & 0.31 \\
\hline
\end{tabular}

Note: Values are presented as mean \pm standard deviation $(\mathrm{mmHg})$.

Abbreviations: POAG, primary open-angle glaucoma.

administered the latanoprost $0.005 \%+$ timolol maleate $0.5 \%$ fixed combination for more than 24 months. In the 1028 cases in which administration was possible for more than 24 months, IOP significantly decreased. IOP-lowering values recorded at $6,12,18$, and 24 months were $4.0 \pm 4.3 \mathrm{mmHg}$, $3.9 \pm 4.5 \mathrm{mmHg}, 4.0 \pm 4.4 \mathrm{mmHg}$, and $4.2 \pm 4.7 \mathrm{mmHg}$, respectively, indicating that IOP-lowering efficacy was preserved over 24 months of administration. According to these reports ${ }^{7-9}$ and the results of the present study, possibly because timolol maleate is contained in the tested fixed combination, IOP-lowering efficacy is maintained throughout 24 months of administration.

Adverse reactions previously reported for the latanoprost $0.005 \%$ + timolol maleate $0.5 \%$ fixed combination include hyperemia, stimulation, foreign body sensation, conjunctivitis, and corneal epithelium disorder. ${ }^{1-5,7-9}$ Most studies, including the present one, reported no serious adverse reactions to the fixed combination eyedrops. ${ }^{1-5}$ Adverse events, such as eye pain, itchiness, stimulation, photophobia, foreign body sensation, headache, and nausea, reported in the present study were almost the same as those reported by previous researchers. ${ }^{1-5,7-9}$ Moreover, the medication was changed from concomitant use to a fixed combination in the present study. Therefore, new distinctive adverse reactions of $\beta$-blocker and prostaglandin analogs did not appear and safety was satisfactory. In our previous study, an IOP decrease of more than $2 \mathrm{mmHg}$ was observed at one (21 patients, $13.0 \%)$ and 3 (29 patients, $20.9 \%$ ) months after changing to the fixed combination. ${ }^{5}$ Similarly, in the present study, IOP decreases $>2 \mathrm{mmHg}$ were found at 6 (27 patients, $19.0 \%$ ) and 12 (31 patients, 23.3\%) months after the change. However, 20 patients discontinued the fixed combination within the first 12 months of administration because of insufficient
IOP-lowering efficacy. In addition, some patients exhibited IOP increases after changing to the fixed combination. These changes are thought to have occurred because timolol maleate $0.5 \%$ was reduced from twice a day to once a day.

In the present study, we also investigated the visual field preservation efficacy of the latanoprost $0.005 \%+$ timolol maleate $0.5 \%$ fixed combination. No significant differences were found between mean deviation values obtained at baseline and 12 months after changing to the new formulation. Schwenn et al evaluated changes in the visual field for 24 months after changing to the latanoprost $0.005 \%+$ timolol maleate $0.5 \%$ fixed combination, using mean defect values and the Aulhorn stage classification. ${ }^{9}$ They found no significant differences in mean defect values, when comparing data obtained at baseline and 6,12, 18, and 24 months after the change. According to Aulhorn stage, 24 months after the change, $59.0 \%$ of patients showed no change in visual field preservation, $18.9 \%$ of patients showed decreased preservation of the visual field, and $22.1 \%$ of patients showed an improvement in visual field preservation. Nevertheless, progression of visual field disorder is usually very slow. Therefore, long-term follow-up is required to document better the effects of the fixed combination on preservation of the visual field.

The weakness of the present study is that ophthalmotonometry was not masked, the effect of medications other than timolol maleate $0.5 \%$ and latanoprost $0.005 \%$ are assumed, and the IOP measurement time was the same in each patient but was not standardized in general. Adherence of patients was checked at every follow-up visit but does not have reliability. Central corneal thickness was not measured, so its influence is not clear. Each factor may have had an influence on IOP. Therefore, the change in IOP was analyzed in 
latanoprost $0.005 \%$ and timolol maleate $0.5 \%$ fixed combination cases only, for primary open-angle glaucoma, normal tension glaucoma, and in cases where cataract surgery was performed and not performed, but there was no change in any of the groups. In conclusion, following 12-month replacement of two eyedrop medications (latanoprost $0.005 \%$ and timolol maleate $0.5 \%$ ) by the latanoprost $0.005 \%+$ timolol maleate $0.5 \%$ fixed combination in patients with primary open-angle glaucoma or ocular hypertension, IOP was preserved and progress of visual field disorder was controlled. However, it should be borne in mind that some patients may experience adverse reactions, such as eye pain, itchiness, and stimulation, or even show increased IOP. Therefore, careful follow-up is required after a change to the fixed combination.

\section{Disclosure}

The authors report no conflicts of interest in this work.

\section{References}

1. Diestelhorst M, Larsson LI; European Latanoprost Fixed Combination Study Group. A 12 week study comparing the fixed combination of latanoprost and timolol with the concomitant use of the individual components in patients with open angle glaucoma and ocular hypertension. Br J Ophthalmol. 2004;88:199-203.

2. Hamacher T, Schinzel M, Schölzel-Klatt A, et al. Short term efficacy and safety in glaucoma patients changed to the latanoprost $0.005 \% /$ timolol maleate $0.5 \%$ fixed combination from monotherapies and adjunctive therapies. Br J Ophthalmol. 2004;88:1295-1298.
3. Polo V, Larrosa JM, Ferreras A, Borque E, Pablo LE, Honrubia FM. Effect on diurnal intraocular pressure of the fixed combination of latanoprost $0.005 \%$ and timolol $0.5 \%$ administered in the evening in glaucoma. Ann Ophthalmol. 2008;40:157-162.

4. Dunker S, Schumcker A, Maier H; Latanoprost/Timolol Fixed Combination Study Group. Tolerability, quality of life, and persistency of use in patients with glaucoma who are switched to the fixed combination of latanoprost and timolol. Adv Ther. 2007;24:376-386.

5. Inoue K, Okayama R, Higa R, et al. Ocular hypotensive effects and safety over 3 months of switching from an unfixed combination to latanoprost $0.005 \% /$ timolol maleate $0.5 \%$ fixed combination. $J$ Ocul Pharmacol Ther. 2011;27:581-587.

6. Boger WP III. Short-term "escape" and long-term "drift": the dissipation effects of the $\beta$-adrenergic blocking agents. Surv Ophthalmol. 1983;Suppl 28:235-242.

7. Rigollet JPK, Ondateui JA, Pasto A, Lop L. Randomized trial comparing three fixed combinations of prostaglandins/prostamide with timolol maleate. Clin Ophthalmol. 2011;5:187-191.

8. Higginbotham EJ, Feldman R, Stiles M, Dubiner H; Fixed Combination Investigative Group. Latanoprost and timolol combination therapy vs monotherapy: one-year randomized trial. Arch Ophthalmol. 2002;120:915-922.

9. Schwenn O, Heckmann B, Guzy C, Miller PJ. Long-term effect of latanoprost/timolol fixed combination in patients with glaucoma or ocular hypertension: a prospective, observational, noninterventional study. BMC Ophthalmol. 2010;10:21.
Clinical Ophthalmology

\section{Publish your work in this journal}

Clinical Ophthalmology is an international, peer-reviewed journal covering all subspecialties within ophthalmology. Key topics include: Optometry; Visual science; Pharmacology and drug therapy in eye diseases; Basic Sciences; Primary and Secondary eye care; Patient Safety and Quality of Care Improvements. This journal is indexed on Submit your manuscript here: http://www.dovepress.com/clinical-ophthalmology-journal

\section{Dovepress}

PubMed Central and CAS, and is the official journal of The Society of Clinical Ophthalmology (SCO). The manuscript management system is completely online and includes a very quick and fair peer-review system, which is all easy to use. Visit http://www.dovepress.com/ testimonials.php to read real quotes from published authors. 